\title{
Enhancing Corrosion Resistance in Explosive Welding
}

\author{
Asna Alam \\ Industrial and Manufacturing Engineering \\ Department, PNEC-National University of Sciences and \\ Technology, Islamabad, Pakistan
}

\author{
M. Nasir Bashir* \\ National University of Sciences and \\ Technology, Islamabad, Pakistan
}

\begin{abstract}
Explosive Welding (EXW) is one of the solid-state joining techniques. A controlled explosion takes place on the surface of the flyer plate, which results in the bonding with base plate. There are basically two type of materials that can be welded together, i.e., similar and dissimilar materials. In this review paper we did a detailed study on the recent work done in this field. We also examined the micro and macro structural properties of the welded composites, briefly. Further we focused on how strong bonding enhanced corrosion resistivity in the composite formed. Detonation velocity plays an important role in the strength of bonding. From the study of all researches referenced in this paper we found that firstly, same element can behave differently in different scenario. Secondly, how bonding between multi-layer elements is depended upon welding position and detonation velocity.
\end{abstract}

Keywords: EXW, similar and dis-similar material, bond strength, detonation velocity, corrosion Resistivity

Received: 14 July 2019; Accepted: 03 September 2019; Published: 25 November 2019

\section{INTRODUCTION}

Over the period many experimental researches have been done. The goal for any review paper is to gather all the experimental information available. Firstly, appreciate the work done already then highlight the gaps. Secondly, suggest how those gaps can be filed by suggesting new possibilities so that the future researcher can easily find what is needed to be done, in a certain field. The purpose of this work is to provide a clear picture of all the recent work done in the field of EXW and what measures are taken to reduce the rate of corrosion.

EXW, its origin dates to World War I, but was developed in the decades later WWII i.e., around 1960s this procedure was used commercially all over the world. It is mainly used to join large areas of one metal with another. The explosive cladding of steel plates is used in chemical and nuclear productions because of their decent corrosion resistance in addition to mechanical properties. This procedure offers feasible solution even for costly applications [1, 2].
EXW is a solid-state process of linking various-layer material together. This technique results in welded linkages from a high-speed diagonal impact, via detonation. During this collision progression, a high-speed surge is initially produced among the surface of base and the flyer plates, which removes the surface oxide layer which contains a damaging effect to the development of chemical bonding of the metals. Then the freshly cleared exteriors are fused together under extreme pressure contacts. Dissimilar and similar materials can be welded by the technique of EXW [3].

Corrosive wear indicates a significant problem in the consumption of any equipment such as in chemical industry in addition to geothermal power plants [4]. The usage of alloys which are resistive to corrosion is generally associated with its cost. However, EXW offers a relatively better solution in this matter because this process doesn't alter properties of materials involved such as, corrosive resistance.

The aim of this review paper is to discuss compat-

\footnotetext{
${ }^{*}$ Correspondence concerning this article should be addressed to M. Nasir Bashir, National University of Sciences and Technology, Islamabad, Pakistan. E-mail: nasir@pnec.nust.edu.pk

(c) 2019 The Author(s). Published by KKG Publications. This is an Open Access article distributed under a Creative Commons AttributionNonCommercial-NoDerivatives 4.0 International License.
} 
ible combination being explosively welded to increase the resistivity to corrosion. We will discuss in detail how bonding strength aides in corrosion resistance and analyze the work done by our predecessors $[5,6]$.

\section{A. Welding Setup}

In EXW, a compression force is created by blast of explosive material and two overlapping metal sheets are joined. The joining parts are placed such that the angle between the ranges from $1-15^{\circ}$, depending on the material. And then a layer of explosive is added over the top. After detonation the areas to be joined are moved opposite each other at a high speed, bonding occurs with formation of local plastic on the contact area (Fig 1).

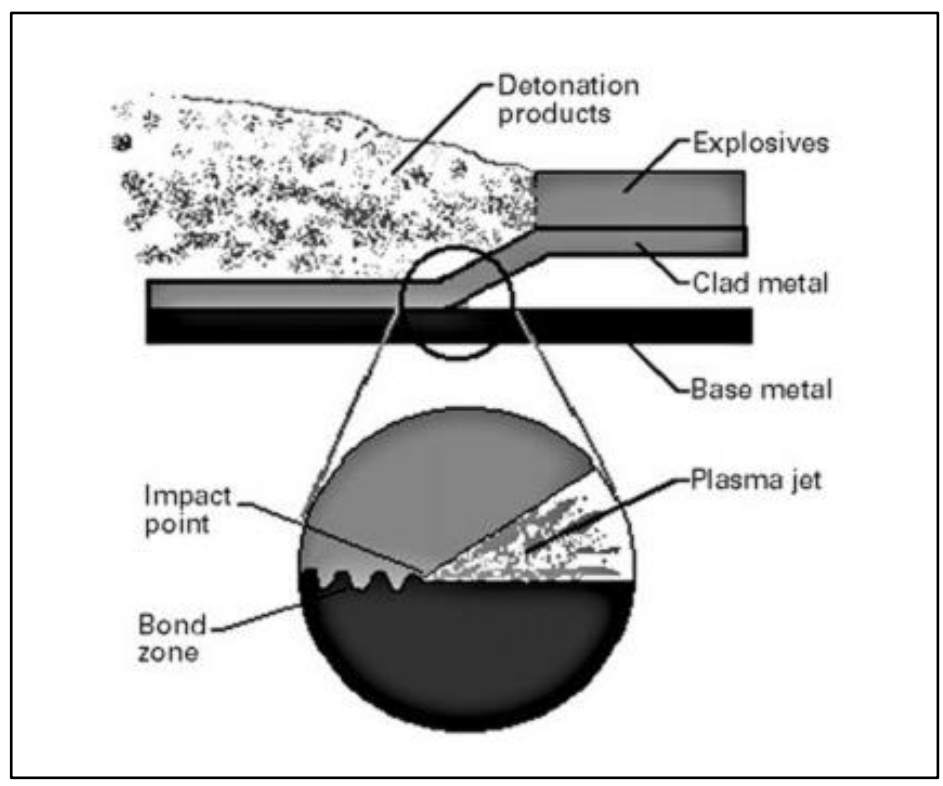

Fig. 1. Function principle of explosion welding

TABLE 1

SPECIFICATIONS OF PARAMETERS INVOLVED IN EXW [7]

Parameters

Thickness of Cladding

Detonation Velocity

Speed at which top plate hits bottom plate

Pressure

Under certain ailment an extremely hot sheet of material forms in the contact area, this joint is then triggered by a deformation-induced melting bath. EXW causes no change in microstructure of any material, so the corrosion resistive property of any material is not degraded by this type of welding technique.

Over 260 numerous dissimilar and similar metals and alloy mixtures can be explosively welded together. Explosive selection and detonation Velocity (Vd) are vital parameters which result in good weld. The bonding interface in EXW presents three morphologies: straight, wavy and melted layer [8]. The qualitative study of these morphologies shows the strength of bonding [9].
Ranges

$0.1-30 \mathrm{~mm}$

$1200-7000 \mathrm{~ms}^{-1}$

$100-1000 \mathrm{~ms}^{-1}$

$10-100 \mathrm{kbar}$

\section{EXPERIMENTAL RESEARCH}

In this section we will discuss and compare recent experimental developments in the field of EXW. We will see that how bonding strength effects corrosion rate and what role EXW technique plays in this matter. Furthermore, we will see what elements were used which showed an improvement in resistance of corrosion.

According to the experimental work performed by Yanni Wei and team, in which they did three types of welding techniques on $\mathrm{Cu} \backslash \mathrm{Al}$ composites: EXW, solidliquid casting technique and cold-pressure welding. We observed that by only using a different technique, 
provides change in behavior of the same elements bonded. Here we will only focus on the results obtained from EXW while the results from other two techniques will be used only to compare [10]

The basic setup involved copper as flyer plate and aluminum as base plate. Approximately, $1.25 \mathrm{~mm}$ was the initial stand-off. Emulsion explosives were used in the process with the ratio of $2: 1$. The $\mathrm{Vd}$ was $2100 \mathrm{~m} / \mathrm{s}$. The thermal shock along with the severe plastic deformation during the procedure enhances the interface reaction and diffusion, so that the metallurgical bond among both components used is formed. The typical interface structure is communicated in Fig 2. Hence, we can visually see from the images below that EXW represents decent bonding without any major macro-defects, as compared to the other two welding techniques [10]

In this section we will discuss and compare recent experimental developments in the field of EXW. We will see that how bonding strength effects corrosion rate and what role EXW technique plays in this matter. Furthermore, we will see what elements were used which showed an improvement in resistance of corrosion.
According to the experimental work performed by Yanni Wei and team, in which they did three types of welding techniques on $\mathrm{Cu} \backslash \mathrm{Al}$ composites: EXW, solidliquid casting technique and cold-pressure welding. We observed that by only using a different technique, provides change in behavior of the same elements bonded. Here we will only focus on the results obtained from EXW while the results from other two techniques will be used only to compare [10].

The basic setup involved copper as flyer plate and aluminum as base plate. Approximately, $1.25 \mathrm{~mm}$ was the initial stand-off. Emulsion explosives were used in the process with the ratio of $2: 1$. The Vd was $2100 \mathrm{~m} / \mathrm{s}$. The thermal shock along with the severe plastic deformation during the procedure enhances the interface reaction and diffusion, so that the metallurgical bond among both components used is formed. The typical interface structure is communicated in Fig 2. Hence, we can visually see from the images below that EXW represents decent bonding without any major macro-defects, as compared to the other two welding techniques [10].
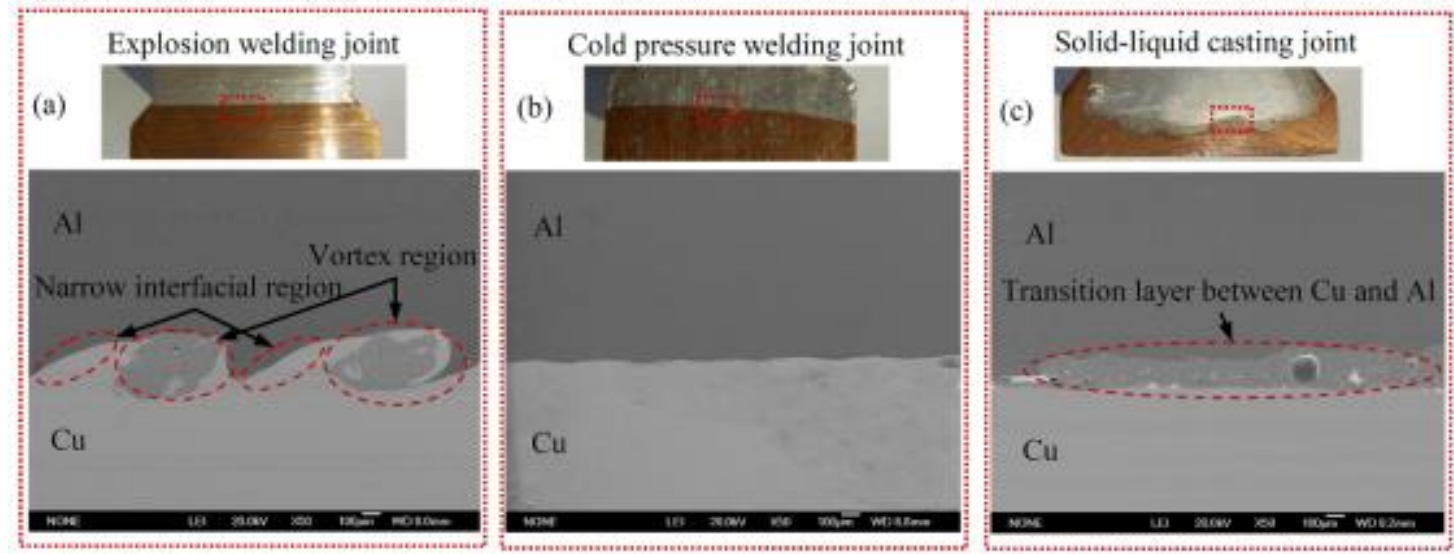

Fig. 2. Three types of interface constructions, (a) EXW, (b) cold pressure welding joint and (c) solid-liquid casting joint [10]

Furthermore, in Table 2. It could be perceived that the self-corrosion current density was minimum in EXW

trial. And Fig. 3 shows a relatively slow corrosion rate.

TABLE 2

THE CORROSION CURRENT DENSITY

Sample Types

EXW

Cold Pressure Welding

Solid-Liquid Casting
Corrosion Current Density $\left(\mathrm{A} / \mathrm{cm}^{2}\right)$

$1.1616 \times 10^{-6}$

$1.1609 \times 10^{-7}$

$4.4508 \times 10^{-6}$ 

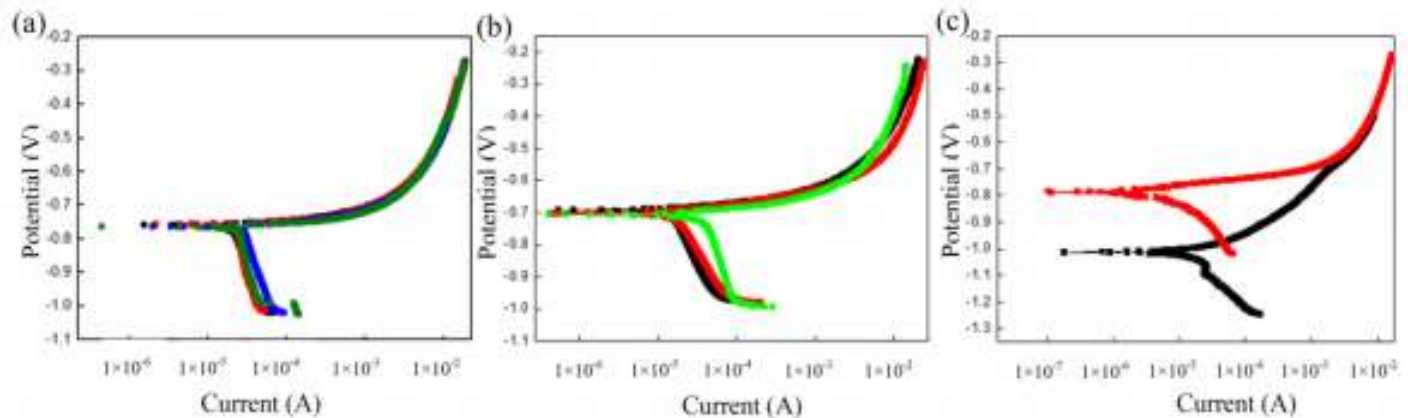

Fig. 3. The interface polarization curve of three types of joints shown as: (a) explosion welding, (b) cold pressure welding and (c) solid-liquid casting [10]

The above comparison concludes the EXW provides reliable bonding strength (104 MPa), and hence reduces corrosion rate.

Moreover, detonation velocity greatly effects bonding mechanisms [11]. This was practically proved by Wei Deng along with his team and Zhao-Hua Jia. In their practical work they compared the bonding mechanism of Ti-Al composite using five different emulsion explosives.
In addition to how the alteration in emulsion effected the bonding interface and other mechanical properties. The basic setup included titanium tube as base tube whereas aluminum is used for flyer tube. The gap between the tube is $1 \mathrm{~mm}$, and inward explosive method was adopted.

Table 3 shows the different $\mathrm{V}_{d}$ of different emulsion explosives and Fig. 4 shows the inner surface morphologies.

TABLE 3

$\mathrm{V}_{D}$ OF EMULSION EXPLOSIVE

\begin{tabular}{lccccc}
\hline Mixture & A & B & C & D & E \\
\hline Detonation Velocity $[\mathrm{m} / \mathrm{s}]$ & 2550 & 2350 & 2150 & 1950 & 1450 \\
\hline
\end{tabular}
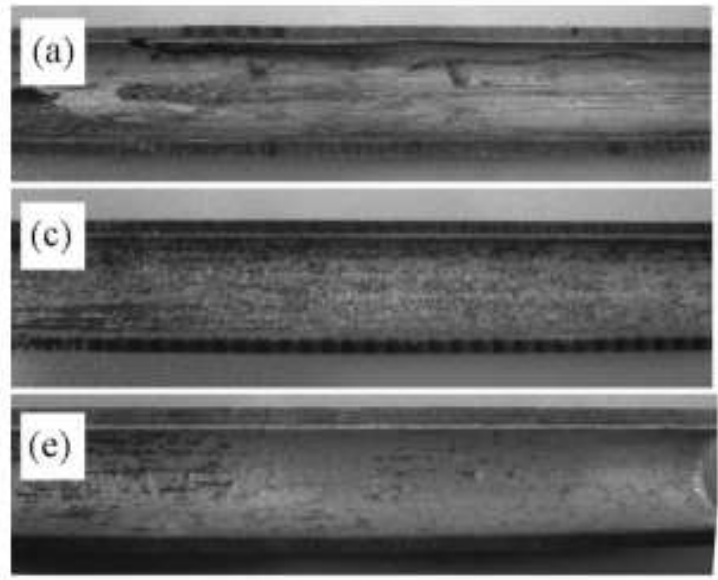

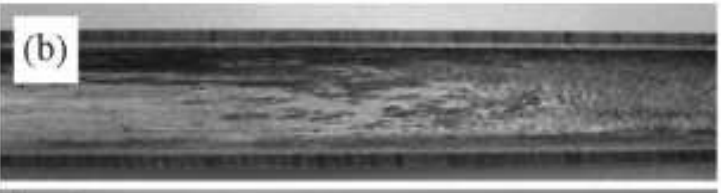

(d)

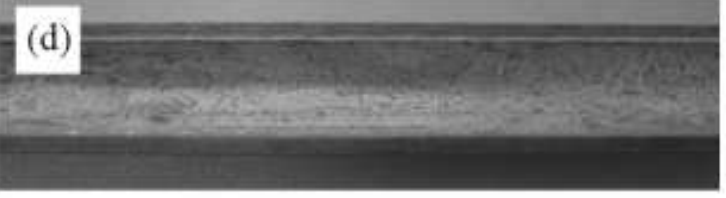

Fig. 4. The internal surface and segment of the composite tubes with different mixture of emulsion explosives corresponding to the Table 3 [11]

It appears that the compounds in Fig. 4(a), (b), and (e) contains some grade of burns, infiltration and no welding. It shows that the three mixtures of explosives cannot meet the required EXW value. Composite tubes in Fig. 4(c) and (d) have a complete structure without any blemishes. Therefore, mixture of emulsion explosive (c) and (d) mention in Table 3 have decent welding result and meet the required quality. Here by, from this experiment we can conclude that appropriate detonation velocity for quality bonding ranges from $1950 \mathrm{~m} / \mathrm{s}$ to $2150 \mathrm{~m} / \mathrm{s}$. Hence, this quality bonding provides better mechanical properties and provide slow corrosion rate $[11,10]$. 
Up till now we have seen that EXW gives better bonding of elements and choosing correct detonation velocity aides in quality bonding of elements. Now we will see how it works in multi-layer structure of the elements needed to be weld.

Moving forward, experimental researchers have only worked on welding plates of similar or dissimilar material, but Ming Yang and his co-workers experimented on welding tantalum foil [3]. It was not only a successful experiment, but corrosion resistive property was also remarkably improved. Now the experimental setup for this involved Ta foil $0.2 \mathrm{~mm}$, as flyer plate and Q235 steel as a base plate.

Since the Ta foil was used, the defects were formed easily. Thus, they improved the conventional EXW from two ends: a structure contained two layers i.e., cardboard with a thin aluminum sheet which was used as shield, sandwiched between the explosive used and tantalum foil. The cardboard was exposed to the explosives directly, which could lessen the thermal damage to flyer plates. The thin aluminum plate was affixed on the Ta foil, which reduced the damage to the tantalum foil. Experimental system is shown below in the Fig. 5 .

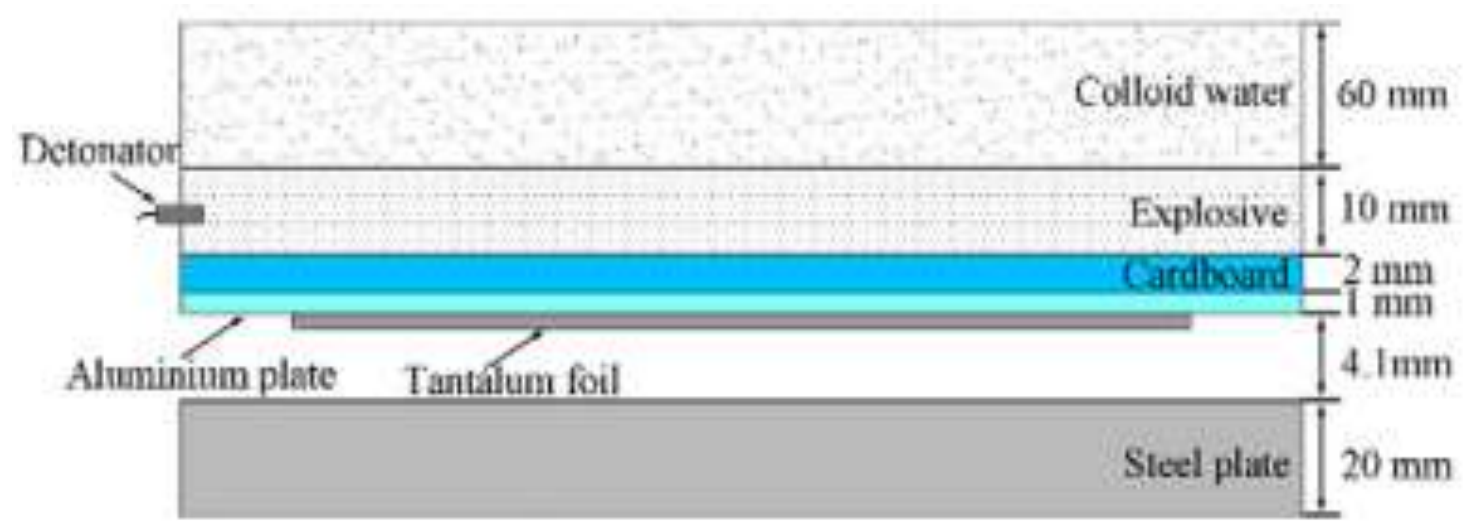

Fig. 5. Trial setup of the improved EXW procedure [3]

Fig. 6 shows BSE visuals of explosively welded joints, ing among Ta foil and q234 plate was attained. a wavy structure can be observed. An outstanding bond-

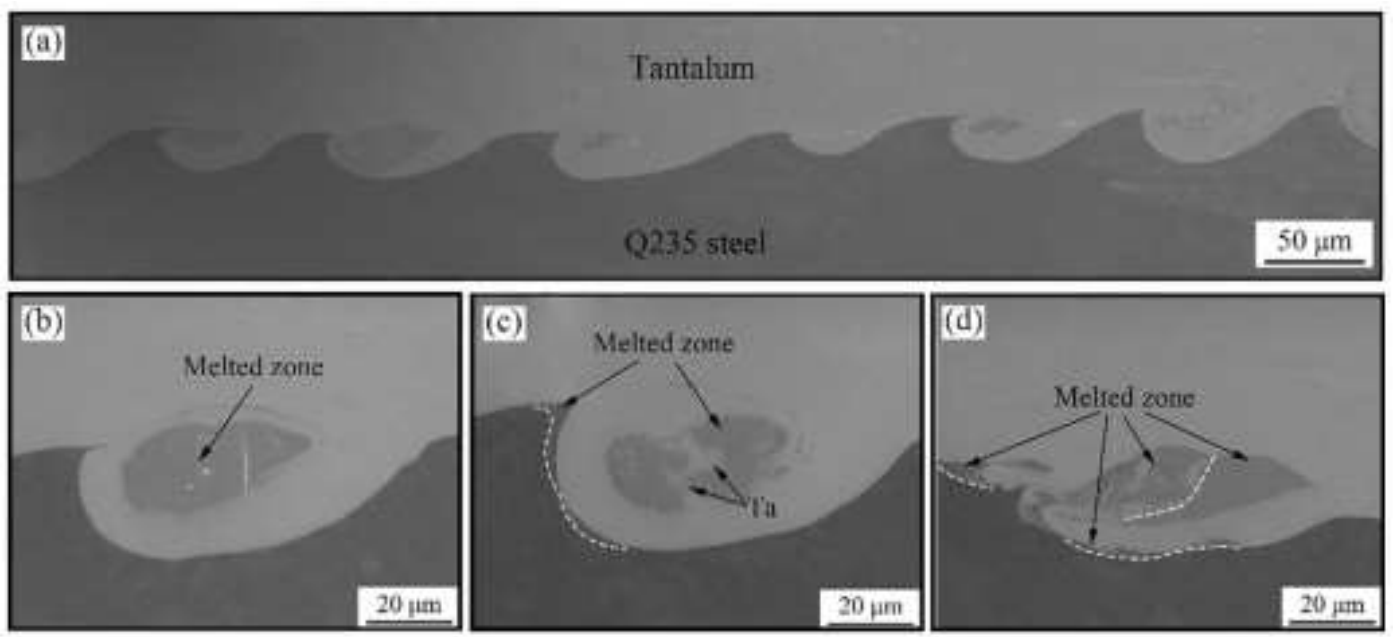

Fig. 6. BSE visuals of the Ta/Fe EXW joints. (a) Overall layout of the wave-type interface, (b-d) Amplified view of the usual crest structure. [3]

It is commonly known that tendency for an element to corrode can be assessed by corrosion potential i.e., greater the potential charge, the stronger the erosion initiation.
Whereas, the corrosion current is directly proportional to corrosion rate. Therefore, the corrosion resistivity was impressively enhanced after a layer of Ta foil was welded. 


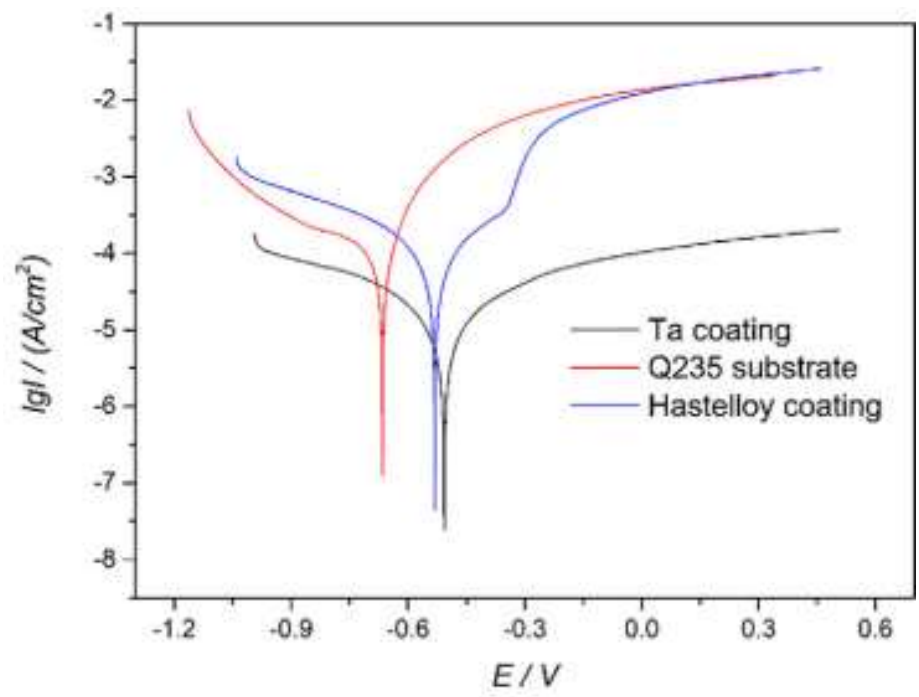

Fig. 7. Potential polarization curves of the three materials [3]

TABLE 4

CORROSION RATE OF TA AND Q235 SUBSTRATE

\begin{tabular}{lll}
\hline Substance & Ta Coating & Q235 Substrate \\
\hline Corrosion rate $/(\mathrm{mm} / \mathrm{a})$ & $0.0084 \pm 0.0009$ & $0.22 \pm 0.02$ \\
\hline
\end{tabular}

Experimental results in Fig. 7 coincides with the corrosion rate listed in Table 4 . Hence it is practically Ta foil can be used to improve corrosion resistivity in DSS materials.

Until now we have only discussed the EXW of bimetallic sheets. Jie Ning and his colleague's experimental found out that $\mathrm{Zr} / \mathrm{Ti} / \mathrm{steel}$ tri-metallic sheets have better service performance in strictly corrosive environments
[12]. Many investigations have proved that zirconium and titanium have corresponding corrosion resistive properties.

The basic setup for this experiment was that the flyer and middle plate were made using commercial pure zirconium and titanium, respectively. Whereas the base plate was formed using $16 \mathrm{Mn}$ low alloy steel.

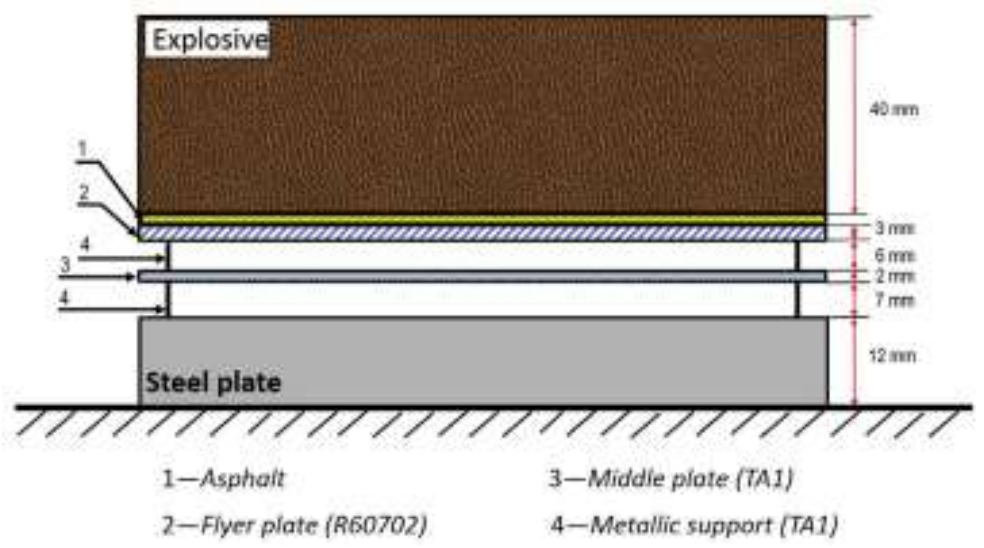

Fig. 8. Illustration of the setup [12]

Two environment conditions were considered while studying corrosion resistivity: first one was a combination of acetic acid, HCL and FeCL3 and the second consisted a blend of acetic acid and KI. After performing corro- sion tests using a CS350 electrochemical workstation. Following results were obtained, shown in the Table 5 below. 
TABLE 5

COMPARISON OF CORROSION RESISTIVITY IN TWO DIFFERENT ENVIRONMENTS

\begin{tabular}{lcccc} 
Material & $\operatorname{Zr}(1)$ & $\operatorname{Ti}(1)$ & $\operatorname{Zr}(2)$ & $\operatorname{Ti}(2)$ \\
\hline Corrosion rate/(mm/a) & 0.379 & 0.108 & 0.013 & 0.015 \\
\hline
\end{tabular}

It can be concluded form the table that corrosive rate of $\mathrm{Zr}$ in environment 1 is larger than Ti. Whereas, Ti rate in environment 2 was larger than $\mathrm{Zr}$.

R. Kosturek and his co-researchers proved the two separate heat treatment trials: normalizing and stress relief annealing. This led to changes in microstructure of the welded piece and resisted corrosion. The process used explosive called ammonium nitrate (V) and Vd was 2700 $\mathrm{m} / \mathrm{s}$. This resulted in welding P355NH and Inconel 625 alloy [4].

Yakup Kaya bonded ship-steel metal (base plate) and aluminum sheet (flyer plate) via EXW [13]. Detonation velocity ranged between $3000-3200 \mathrm{~m} / \mathrm{s}$. Erosion resistance was tested by seawater in other words Neutral Salt Spray (NSS) was used. The test results proved that aluminum cladded to ship-steel showed better resistance as compared to that of ship steel. Fig. 9 Show the compound samples after NSS test performed. After 24 hours, the examination revealed corrosion in ship-steel side of the composite, while no corrosion was detected on the aluminum side. After 48 hours, the ship steel side of the composite was almost corroded whereas the aluminum side still maintained its corrosion resistance.

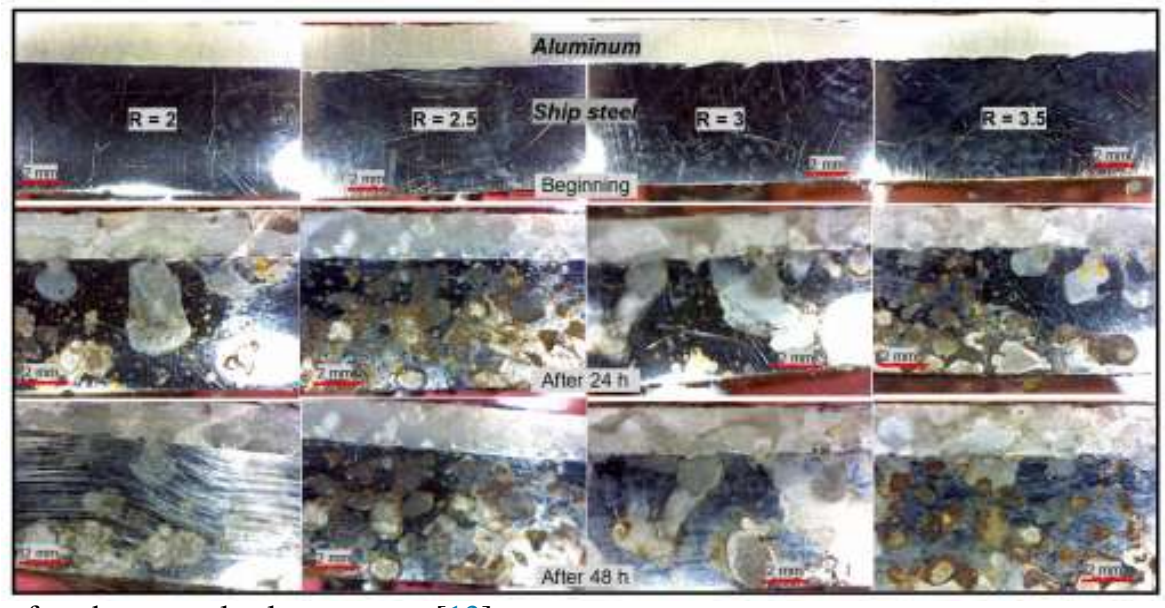

Fig. 9. Macro images after the neutral salt spray test [13]

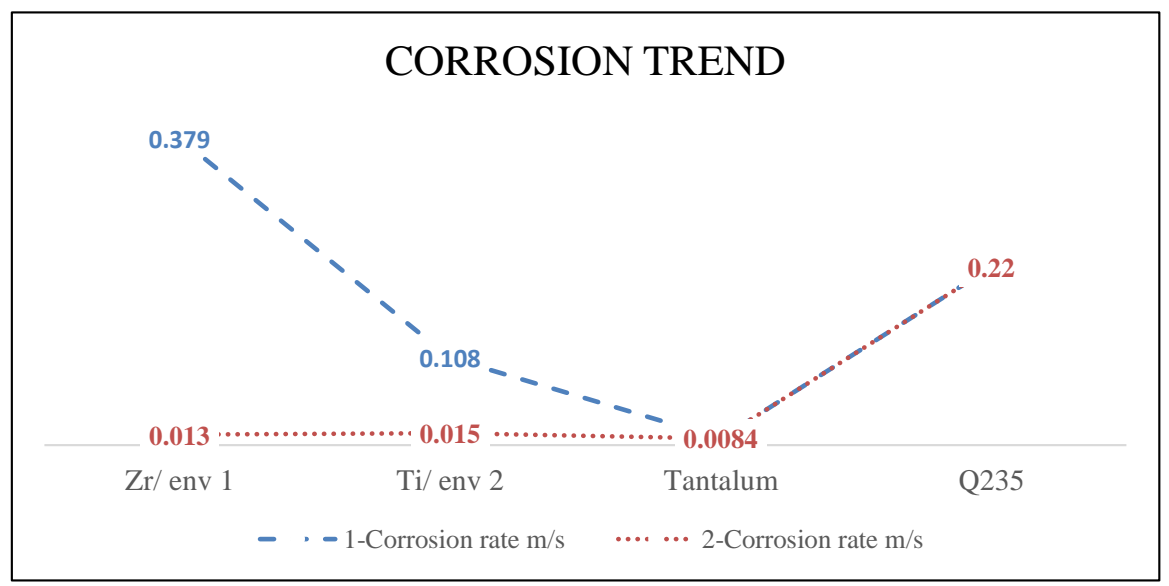

Fig. 10. Corrosion trend comparison 
From the graph in Fig. 10 shown above it is clear the tantalum corrodes extremely slowly.

Moreover, strength on corrosion resistivity is affected when exposed to hydrogen charging. It has a destructive impact and causes significant changes on the microstructure of the explosively joined dissimilar plates. The hydrogen induced blisters and microcracks [14].

Welding of dissimilar material is highly dependent on how they are positioned i.e., as the baseplate or the flyer plate. This also defines the range of energy which can be used to weld them [15].

From the study of all researches referenced in this paper we found that firstly, same element can behave differently in different scenario. Secondly, how bonding between multi-layer elements is depended upon welding position and detonation velocity.

\section{CONCLUSION}

Researchers in every field are constantly doing commendable extensive practical work. Similarly, scientists of this field are continuously working on how to improve already existing EXW techniques of all kind of material combination i.e., similar and dissimilar materials, how techniques can be improved so that welded piece show better mechanical properties. After reviewing many papers in this regard, few are discussed in detail as they are most closely related to our work of interest.

We know that metal corrode differently in different industrial environments, so the suggestions are based on their basic corrosion resistive property. Zirconium and titanium show different rate of corrosion in two types of acetic acid industry environments. Although they have commendable slow rate of corrosion, but it changes depending upon the circumstances [12].

Further appropriate detonation velocity gives strengthened bonding [11]. Hence, provide high corrosion resistance. Similarly, aluminum provide better resistance to seawater when used with ship-steel $[13,16]$.

\section{FUTURE SCOPE}

Here, after a thorough study of the work done in past decade. We will now purpose some suggestions which can be practically implemented in future work of EXW with better resistance to corrosion.

a) Future researcher can apply this improved setup of EXW and weld three layer dis-similar material $[3,12,17]$. It might provide improved results.

b) Combination of tantalum foil, aluminum and ship steel welded together can provided better results in corrosion resistivity as we know they both individually have better response to corrosion. Further, the combi- nation they might be able to work with are mentioned $[3,12,13,17]$.

These are just proposition which work hypothetically, but will they work in real world and provide better results is subject to the success of these experiments if performed in future.

\section{REFERENCES}

[1] T. Tokunaga, M. Ohno, and K. Matsuura, "Coatings on mg alloys and their mechanical properties: A review," Journal of Materials Science \& Technology, vol. 34, no. 7, pp. 1119-1126, 2018. doi: https://doi.org/10.1016/j.jmst.2017.12.004

[2] J. Verma and R. V. Taiwade, "Effect of welding processes and conditions on the microstructure, mechanical properties and corrosion resistance of duplex stainless steel weldments-a review," Journal of Manufacturing Processes, vol. 25, pp. 134-152, 2017. doi: tps://doi.org/10.1016/j.jmapro.2016.11. 003

[3] M. Yang, H. Ma, Z. Shen, Z. Huang, Q. Tian, and J. Tian, "Dissimilar material welding of tantalum foil and Q235 steel plate using improved explosive welding technique," Materials \& Design, vol. 186, pp. 1-12, 2020. doi: https://doi.org/10.1016/j. matdes.2019.108348

[4] R. Kosturek, M. Wachowski, L. Śnieżek, M. Gloc, and U. Sobczak, "The effects of the heat treatment on the microstructure of inconel 625/steel bimetal joint obtained by explosive welding," in MATEC Web of Conferences, Barcelona, Spain, 2018. doi: https://doi.org/10.1051/matecconf/201824201007

[5] G. Costanza, M. E. Tata, and D. Cioccari, "Explosion welding: Process evolution and parameters optimization," in Materials Science Forum, vol. 941. Trans Tech Publ, 2018. doi: https://doi.org/10.4028/ www.scientific.net/msf.941.1558 pp. 1558-1564.

[6] H.-C. Lu and M.-C. Ho, "A study on designing the identity of a product," Journal of ICT, Design, Engineering and Technological Science, vol. 1, no. 2, pp. 48-55, 2017. doi: https://doi.org/10.33150/jitdets-1. 2.4

[7] F. Mahi and U. Dilthey, "Joining of metals," in Encyclopedia of Materials: Science and Technology, U. Dilthey, Ed. Amsterdam, Netherlands: Elsevier, 2016.

[8] X. Chen, X. Li, X. Wang, H. Yan, K. Li, and $\mathrm{X}$. Zeng, "Bonding mechanism of explosive compaction-welding sintering," Journal of Manufacturing Processes, vol. 46, pp. 1-15, 2019. doi: https://doi.org/10.1016/j.jmapro.2019.08.018 
[9] F. Findik, "Recent developments in explosive welding," Materials \& Design, vol. 32, no. 3, pp. 1081-1093, 2011. doi: https://doi.org/10.1016/j. matdes.2010.10.017

[10] Y. Wei, H. Li, F. Sun, and J. Zou, "The interfacial characterization and performance of $\mathrm{Cu} / \mathrm{Al}-$ conductive heads processed by explosion welding, cold pressure welding, and solid-liquid casting," Metals, vol. 9, no. 2, pp. 1-13, 2019. doi: https://doi.org/10.3390/met9020237

[11] W. Deng, J. H. Lei, W. L. Qu, and Z. H. Jia, "Research on the characteristics of Ti-Al composite tube by explosive welding," in Materials Science Forum, vol. 861. Trans Tech Publ, 2016. doi: https:// doi.org/10.4028/www.scientific.net/msf.861.166 pp. $166-170$.

[12] J. Ning, L.-j. Zhang, M.-x. Xie, H.-X. Yang, X.-q. Yin, and J.-x. Zhang, "Microstructure and property inhomogeneity investigations of bonded $\mathrm{Zr} / \mathrm{Ti} / \mathrm{steel}$ trimetallic sheet fabricated by explosive welding," Journal of Alloys and Compounds, vol. 698, pp. 835-851, 2017. doi: https://doi.org/10. 1016/j.jallcom.2016.12.213

[13] Y. Kaya, "Microstructural, mechanical and corrosion investigations of ship steel-aluminum bimetal composites produced by explosive welding," Metals, vol. 8, no. 7, p. 544, 2018. doi: https://doi.org/10. 3390/met8070544

[14] M. Gloc, H. Słomińska, and Ł. Ciupiński, "Hydrogen influence on microstructure and properties of novel explosive welded corrosion resistant clad materials," Defect and Diffusion Forum, vol. 382, pp. 167-172, 2018. doi: https://doi.org/10.4028/www. scientific.net/DDF.382.167

[15] G. Carvalho, I. Galvão, R. Mendes, R. Leal, and A. Loureiro, "Influence of base material properties on copper and aluminium-copper explosive welds," Science and Technology of Welding and Joining, vol. 23, no. 6, pp. 501-507, 2018.

[16] Y. Kaya, N. Kahraman, A. Durgutlu, and B. Gülenç, "Investigation of the microstructural, mechanical and corrosion properties of grade a ship steel-duplex stainless steel composites produced via explosive welding," Metallurgical and Materials Transactions A, vol. 48, no. 8, pp. 3721-3733, 2017. doi: https://doi.org/10.1007/s11661-017-4161-3

[17] N. Zhou, J. Jiang, K. Tang, and S. Z. Tang, "Study on fabrication and bonding interface of explosive welded steel/aluminum/steel composite plate," Key Engineering Materials, vol. 753, pp. 188-193, 2017. 